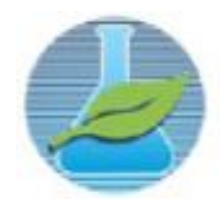

$\mathrm{JCEC} / \mathrm{REQ}^{2}$

Journal

ISSN: 2446-9416

"EU, A INDÚSTRIA E O MUNDO"

08 a 11 de novembro de 2016 no campus Viçosa da UFV

Departamento de Engenharia de Produção e Mecânica - DEP

Universidade Federal de Viçosa - UFV

\title{
ANÁLISE DO ENSAIO DE TRAÇÃO EM CHAPAS DE AÇO 1020 SOLDADAS POR ELETRODO REVESTIDO
}

\author{
Aurélio de Rezende Teixeira, Amanda Figueirêdo Assis \\ Universidade Federal de Viçosa, Departamento de Engenharia de Produção e Mecânica \\ Ph. Rolfs s/n - 36570-000 - Viçosa - MG \\ aurelio.teixeira@ufv.br, amanda.assis@ufv.br
}

\section{INTRODUÇÃO}

Segundo Marques (2009) existem dois métodos principais de união de metais. Um baseado em forças macroscópicas entre as partes que se deseja unir, como parafusos e rebites. O segundo é baseado em forças microscópicas, ou seja, a união é conseguida pela aproximação de átomos e moléculas dos materiais que se deseja unir, como a soldagem, brasagem e a colagem. O processo de união de metais mais importante na indústria é a soldagem. Esta é uma operação de união que visa manter na junta a continuidade das propriedades físicas e mecânicas. Durante o projeto de peças a seleção de um método de união está relacionado à um motivo relevante. Um exemplo é a economia que pode ser obtida, selecionando-se o procedimento correto, na soldagem de peças de seção reduzida (Budynas, 2011).

Assegurar a qualidade de uma junta soldada é muito importante, para garantir que esta possua as propriedades mecânicas mínimas para que possa ser aplicada sem risco (Pinto, 2010). Ensaios destrutivos e não destrutivos podem ser realizados para assegurar que as condições desejadas foram atendidas. Dentre os ensaios destrutivos um que se encontra amplamente disseminado na indústria é o ensaio de tração. Este ensaio consiste na aplicação de uma carga axial crescente de tração que é aplicada até a ruptura do material. Até que se atinja uma carga máxima, próxima ao fim do ensaio, pode-se afirmar que as deformações são praticamente uniformemente distribuídas. (Dalcin, 2007).

\section{OBJETIVO}

O principal objetivo deste artigo é averiguar a curva de Tensão versus Deformação obtida em aço AISI 1020 após um procedimento de soldagem. Tal estudo irá permitir validar a área soldada caso não haja ruptura local

\section{MATERIAIS E MÉTODOS}

\subsection{Materiais utilizados}

- 2 chapas de aço AISI 1020;

- Máquina de Soldagem IMC SOLDAGEM;

- Eletrodo revestido 6013;

- Máquina de ensaio de tração EMiC;

- Computador com software para aquisição de dados do ensaio de tração.

\subsection{Metodologia aplicada}


Primeiramente, soldou-se as duas placas de aço AISI 1020 utilizando o eletrodo revestido 6013. A solda, no entanto, foi feita sem nenhum dimensionamento apropriado para que se pudesse realizar o teste de tração e para que fosse possível observar se a ruptura ocorreria de fato fora da solda. Após o primeiro teste de tração as mesmas chapas foram cortadas novamente para que fosse possível refazer o procedimento de soldagem. A Fig. 1 representa o estado das chapas com um chanfro de 30 graus em ambos procedimentos.

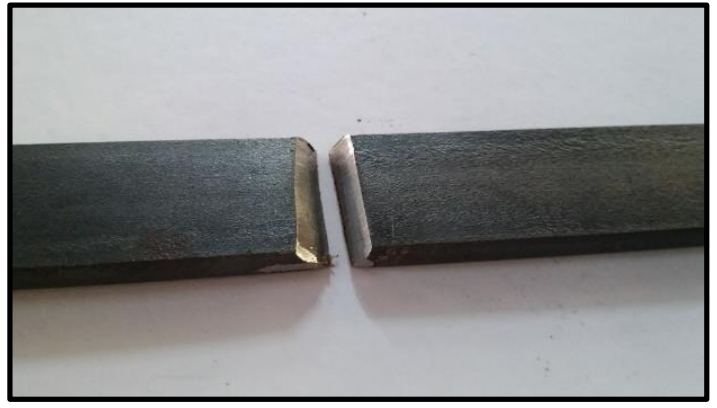

Figura 1 - Chapas de aço AISI 1020 com chanfro de 30 graus

Desta forma, o procedimento foi refeito, porém com um dimensionamento mais detalhado da futura solda e maior espaçamento entre as duas chapas. Estas mudanças foram feitas com o mesmo objetivo de que a ruptura ocorreria fora da solda, agora melhor projetada. A Fig. 2 apresenta a máquina de tração utilizada para o teste.

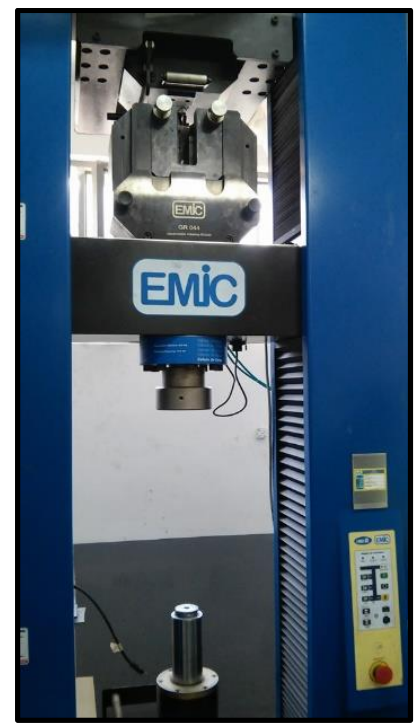

Figura 2 - Máquina de ensaio de tração EMiC

Os dados foram captados durante o ensaio de tração e plotados em um gráfico, que teria como objetivo mostrar a deformação da chapa soldada em relação à tensão então aplicada, até atingir sua ruptura.

\section{ANÁLISE E RESULTADOS}

A Fig. 3 mostra a curva Tensão versus Deformação obtido no ensaio de tração do material soldado. 


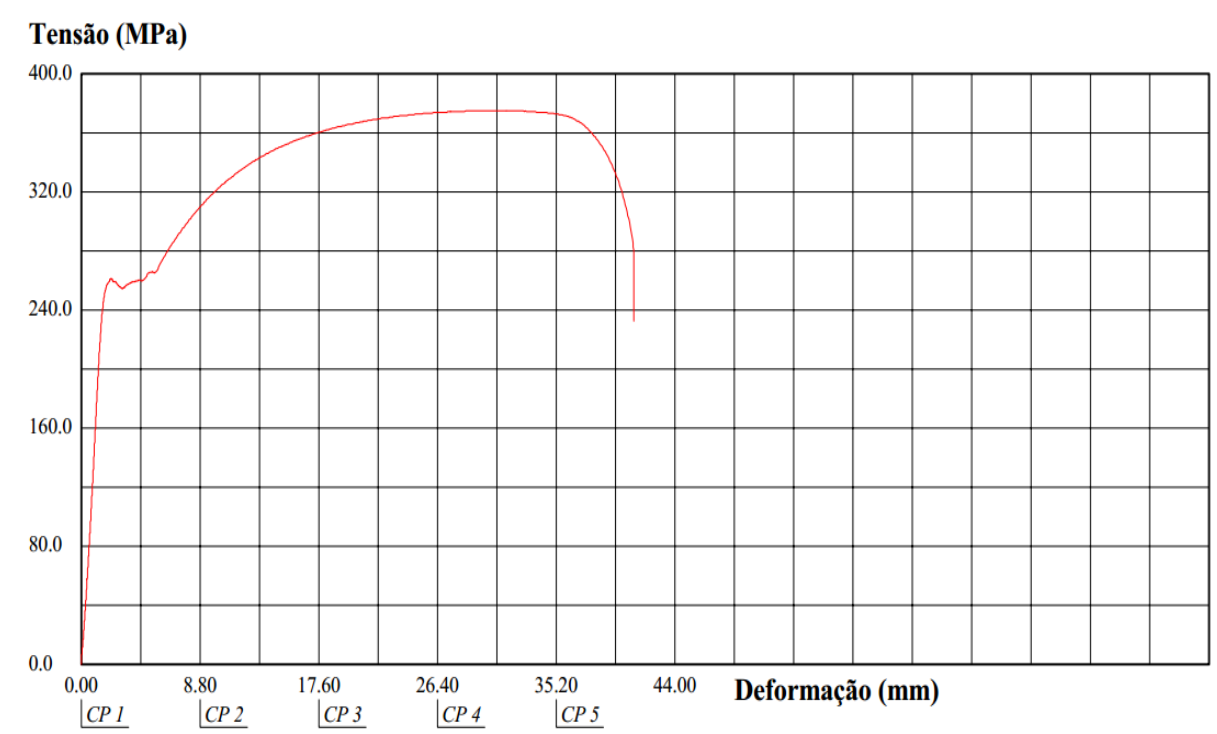

Figura 3 - Gráfico Tensão X Deformação das placas de aço AISI 1020 soldadas.

A curva obtida no ensaio de tração mostra todos os patamares muito bem nítidos até o ponto onde ocorreu a ruptura. É possível verificar que a tensão última do material soldado, aço AISI 1020, é de 375,36 MPa. Comparando com valores teóricos em que a tensão última do aço AISI 1020 é de $420 \mathrm{MPa}$, conclui-se que o valor obtido está dentro dos padrões esperados.

$\mathrm{O}$ fato do aço AISI 1020 ter se rompido antes que a solda se rompesse mostra que a tensão última da solda é maior que a do material. Isto comprova que a tensão última da solda está de acordo com os valores teóricos encontrados, que é de $427 \mathrm{MPa}$.

\section{CONCLUSÃO}

Através do ensaio de tração foi possível validar a solda feita. Os estudos mostraram que as placas de aço AISI 1020 mantiveram-se unidas e, o ponto de solda não foi o mais favorável de falha durante o ensaio. Isto mostra que a tensão última do material das placas (aço AISI 1020) era menor que a tensão última da solda feita pelo técnico, como era desejado ao realizar este processo de união.

\section{AGRADECIEMTOS}

Agradecemos ao Departamento de Engenharia Civil por ceder seus equipamentos e laboratório, ao Departamento de Engenharia de Produção e Mecânica da Universidade Federal de Viçosa e aos envolvidos na disciplina Elementos de Máquina II (MEC352, 2016/2) por todo o apoio na realização do trabalho.

\section{REFERÊNCIAS}

BUDYNAS, R.G. "Elementos de Máquinas de Shigley: Projeto de Engenharia Mecânica". 8 ed. Porto Alegre: AMGH, 2011.

DALCIN, G.B. "Ensaios dos materiais". URI, Santo Ângelo, 2007. Disponível em: <http://www.urisan.tche.br/ lemm/arquivos/ensaios_mecanicos. pdf>. Acesso em 22 de setembro de 2016.

MARQUES, P.V; Modenesi, P.J; Bracarense, A.Q. "Soldagem: Fundamentos e Tecnologia". 3 ed. Belo Horizonte: Editora UFMG, 2009.

PINTO, S.F. “Tecnologia de Soldagem”. IFMG, Congonhas, 2010. 